\title{
Comparative Analysis Of Learning Outcomes In Face-To-Face Foreign Language Classes Vs. Language Lab And Online
}

Claudia S. Salcedo, Southeastern Louisiana University, USA

\begin{abstract}
Action research was conducted for two consecutive semesters comparing beginning level Spanish courses taught in the traditional classroom and the same class taught exclusively in the language lab. A subsequent semester compared an intermediate class taught in the traditional classroom compared to the same class conducted online. Assessment scores were compared for quizzes, tests, oral interview and final exam. Overall course GPA and student opinions were also compared. Identical treatments showed the classroom performed significantly better than the lab class yet the following semester showed the lab performing better but not at a significant level. A second study compared a higher level of students for classroom vs. online. This study showed the classroom performance was better in three out of four assessments, however this difference was not significant.
\end{abstract}

Keywords: foreign language, face-to-face, language lab, online, class performance

\section{INTRODUCTION}

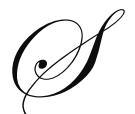

tudies comparing classroom instruction to other computer-assisted learning have varying results. Arbaugh (2000) showed no significant difference in learning in either class section reporting the results of comparing a classroom-based and an Internet-based MBA class section. Caywood (2003) also found no significant differences between online vs. on-campus groups in the measurement of initial learning or follow-up performance. According to Schutte (1997) and Johnson, et. al (1999), the students in the face-to-face course held more positive perceptions about the instructor and overall course quality, although there was no difference between the two-course formats in learning outcomes.

Others report on better performance when instruction is computer-based. A study by Schutte (1997) showed that instruction provided online can result in improved performance. That study also showed that the faceto-face group provided more positive ratings than the online group. Face-to-face students also had a more favorable opinion of the amount and type of interactions among the students. The findings show that online learning can be as effective as face-to-face learning in spite of the fact that students in online programs are less satisfied with their experience than students in more traditional learning environments' (p. 7). Sims \& Schuman (1999) also reported that although pre-tests scores were higher for online students, the post-test scores showed no significant differences in instructional effectiveness. In a study by (Cahill \& Catanzaro), students' performance means were compared on writing achievement. Both groups received two identical essays on the final exam. They reported that the online group significantly outperformed those in the in-class group on both measures of writing quality. In an earlier study, analysis of effectiveness of computer-based instruction by Kulik (1994) indicated that the average student receiving computer based instruction performed better than the average student in a conventional class.

These studies, including others that summarize various findings, are mostly all from content areas other than foreign languages. Those comparisons that are reported are, in most cases, descriptive and qualitative. A 
summary of research literature on online teaching and learning done by Tallent-Runnels, et. Al (2006) concluded that most studies reviewed were descriptive and that most online students are non-traditional and Anglo-American. Also, of all the content areas reviewed in that study, none included foreign languages.

One of the main pedagogical objections many teachers have to online foreign language learning is that the oral proficiency of students would suffer. In a study by Blake, et. al (2008), they examine a first-year Spanish course at the University of California via Spanish Without Walls $(S W W)$. This is different from most online courses in that it includes chat sound, graded phone tests, and other ways of assessing oral proficiency that the basic creation of an online course would not offer.

The basic facts about L2 development have not changed; i.e. the road to advanced proficiency is arduous, requiring anywhere from 600 to 2,200 hours of instruction (Bialystok \& Hakuta, 1994 as reported in Blake 2008). Hybrid and distance learning language classes require a high degree of self-motivation and independent work skills. This may account for the high dropout rate for the learning environment in all disciplines (Carr, 2000; Dreyer, Bangeni \& Nel, 2005 as reported in Blake 2008). Individual t-tests given revealed no significant differences among hybrid, distance learning or their classroom counterparts. They state that distance learning is a worthy task for the FL profession showing that students are not being disadvantaged by taking Spanish in a non-traditional format. However, they also state that the interest in distance learning must be situated within a proper L2 developmental context; i.e. the process of L2 acquisition will take students numerous hours of instruction and eventually will require study abroad (emphasis added).

This author's study outlines the statistical results of a comparative analysis of students' performance scores in four areas and also compares the treatment methods for beginning and intermediate Spanish courses. For the first study, students in the traditional classroom were compared with those taught in the language lab.

The language learning lab was equipped with 35 student stations connected to the Sanako teacher control system. Through the use of this system, instruction was administered through multimedia activities, listening, web sites, textbook CD-ROMs, satellite TV programs, Audio CDs, and many student recordings, either individually, in pairs, or in groups. It was theorized that the lab students would perform better by receiving instruction in the multimedia language lab, especially on listening tasks and oral recordings due to their comfort level with the voice recording equipment and that they had more use of these activities during the semester. It must be noted, however, that there were extensive technological problems with the system and class time lost due to changing the lesson plan.

A second study was conducted comparing the same four assessment areas with classroom students and online students. The level of Spanish was higher and the students were probably more comfortable with the online environment since our university holds many distance education classes through a course management system.

The classroom and the online students completed the tests and the oral interview in person in the same format. Quizzes were given to classroom students in written form, while online students completed the identical quiz in an online version through Blackboard.

I will also discuss comments made by students and the instructor experience in these courses. Treatment method, scores and grade point averages will be compared statistically.

\section{MATERIALS AND METHODS}

\section{Participants}

CLASSROOM VS. LAB, 2003

A convenience sample of 43 students ( 24 female, 19 males) at Southeastern Louisiana University was used as participants in the present study. Participants were enrolled in Spanish 101 classroom format or laboratory format. 


\section{Procedure}

The present study aimed at assessing the performance of students in a Spanish 101 course specifically investigating eventual differences in students' performance when the curriculum is delivered in a classroom face-toface format versus laboratory format. In order to investigate the researcher's question, a variable representing the teaching method has been created, this variable was entered with two levels classroom vs. laboratory. Further, four different variables quizzes, exams, oral and final have been created in order to represent the assessment type used to test students' knowledge. A 2 (teaching method) X 4 (assessment type) mixed factorial repeated measures analysis of variance has been conducted; the variable teaching method has been entered into the analysis as a betweensubject factor, the variables quizzes, exams, oral and final have been entered into the analysis of variance as a within-subject factor with 4 levels. Additionally, a series of paired samples Student's tests were conducted to determine which, if any, combination of means for quizzes, exams, oral and final were significantly different amongst the students enrolled in the classroom format versus those enrolled in the laboratory format; a correction with Bonferroni's method has been necessary to correct for type I error and obtain the adjusted alpha level. Further, to observe any overall difference in students' mean performance relative to teaching method, a third variable G.P.A. has been created to represent students' course G.P.A. and used to compute an independent Student's test.

\section{Results}

A 2 (teaching method) X 4 (assessment type) mixed factorial repeated measures analysis of variance has been conducted to assess whether students' performance in Spanish 101 would differ based on the class format, classroom versus lab, to which they were exposed. The analysis showed a significant main effect for assessment $(F$ $=9.663, p=0.000$ ); which suggests that the assessment type used to test students affects their performance. Further, significant differences have been observed across conditions between quizzes $(M=77.514, S D=11.896)$ and final $(M=81.279, S D=11.383)$ and oral $(M=73.162, S D=11.034)$ and final. The results of the analysis of variance reported significant main effect for teaching method $(F=5.012, p=0.031)$ suggesting that the teaching method does affect students' performance. Additionally, no significant interaction has been found between assessment type and teaching method $(F=1.232, p=0.298)$.

Additional analyses were performed to determine the presence of eventual differences between classroom G.P.A. and laboratory G.P.A; the results did not yield a significant G.P.A. difference $(t=-1.515, p=0.137)$ between lab $(M=76.826)$ and classroom $(M=80.912)$. Table 1 shows the class means for the four assessments as compared to the teaching method.

Table 1: Descriptive Statistics, 2003

\begin{tabular}{|l|l|c|c|c|}
\hline \multicolumn{2}{|c|}{ Teaching method } & mean & std. deviation & N \\
\hline quizzes & lab & 74.1684 & 12.24232 & 19 \\
& classroom & 80.1625 & 11.16255 & 24 \\
& total & 77.514 & 11.89699 & 43 \\
\hline exams & lab & 76.7526 & 10.54574 & 19 \\
& classroom & 79.5667 & 10.64346 & 24 \\
& total & 78.3233 & 10.56873 & 43 \\
\hline oral & lab & 68.5947 & 12.02703 & 19 \\
& classroom & 76.7792 & 8.84691 & 24 \\
& total & 73.1628 & 11.03479 & 43 \\
& lab & 77 & 9.64365 & 19 \\
& classroom & 84.6667 & 11.69417 & 24 \\
\end{tabular}

The larger sample size could be a contributing factor to the significant difference in teaching methods. Chart 1 provides a visual representation of the comparative assessment scores for the face-to-face and lab classes. 
Chart 1: 2003 Classroom vs. Lab Assessment Scores

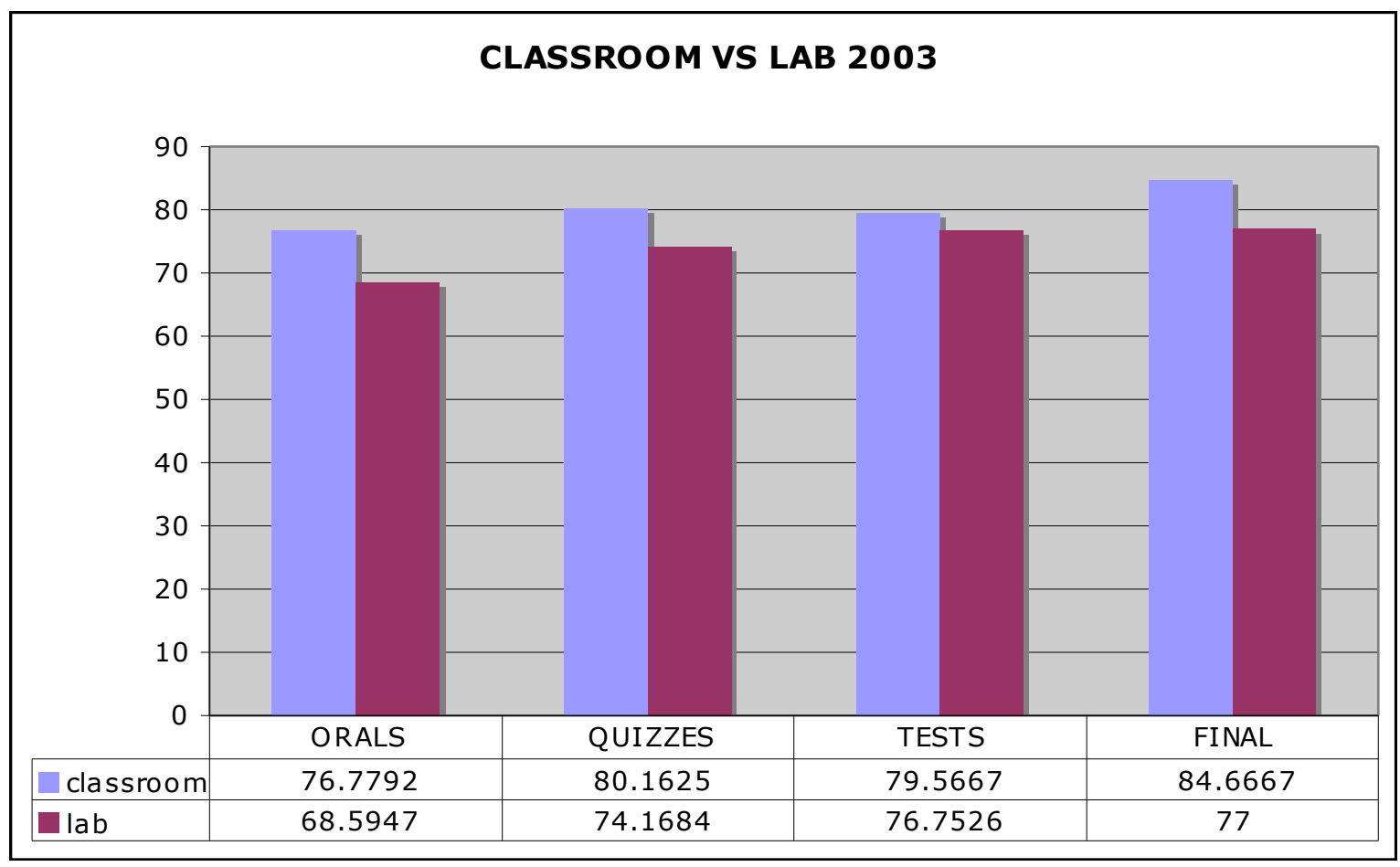

\section{Participants}

\section{CLASSROOM VS. LAB 2004}

A convenience sample of 35 students (25 female, 10 males) at Southeastern Louisiana University was used as participants in the present study. Participants were enrolled in Spanish 101 classroom format or laboratory format.

\section{Procedure}

The present study aimed at assessing the performance of students in a Spanish 101 course specifically investigating eventual differences in students' performance when the curriculum is delivered in a classroom face-toface format versus laboratory format. In order to investigate the researcher's question, a variable representing the teaching method was created, this variable was entered with two levels; classroom vs. laboratory. Further, four different variables quizzes, exams, oral and final have been created in order to represent the assessment type used to test students' knowledge. A 2 (teaching method) X 4 (assessment type) mixed factorial repeated measures analysis of variance was conducted; the variable teaching method has been entered into the analysis as a between-subject factor, the variables quizzes, exams, oral and final have been entered into the analysis of variance as a within-subject factor with 4 levels. Additionally, a series of paired samples Student's tests were conducted to determine which, if any, combination of means for quizzes, exams, oral and final were significantly different amongst the students enrolled in the classroom format versus those enrolled in the laboratory format; a correction with Bonferroni's method has been necessary to correct for type I error and obtain the adjusted alpha level. Further, to observe any overall difference in students' mean performance relative to teaching method, a third variable G.P.A. has been created to represent students' course G.P.A. and used to compute an independent Student's test. 


\section{Results}

A 2 (teaching method) X 4 (assessment type) mixed factorial repeated measures analysis of variance was conducted to assess whether students' performance in Spanish 101 would differ based on the class format, classroom versus internet, they have been exposed to. The analysis showed a significant main effect for assessment $(F=$ 30.652, $p=0.000$ ) which suggests that the assessment type used to test students affects their performance. Further, significant differences were observed across conditions between quizzes $(M=79.571, S D=11.024)$ and exams $(M=$ $75.457, S D=10.589)$; quizzes and oral $(M=67.914, S D=9.589)$; exams and oral; oral and final $(M=81.028, S D=$ 10.708).

The results of the analysis of variance did not report a significant main effect for teaching method $(F=$ 0.072, $p=0.790$ ) suggesting that the teaching method does not affect students' performance. Additionally, a significant interaction has been found between assessment type and teaching method $(F=3.681, p=0.015)$, which suggests that the influence of assessment type on the students' performance depend on the teaching method to which the students were exposed.

Supplemental analysis were performed to determine the presence of eventual differences between classroom course G.P.A. Additional analysis was performed to determine the presence of eventual differences between classroom G.P.A. and laboratory G.P.A; the results did not yield a significant G.P.A. difference $(t=0.379$, $p=0.707)$ between lab $(M=78.352)$ and classroom $(M=77.222)$. Table 2 shows the four assessment scores as compared to teaching method.

Table 2: Descriptive Statistics, 2004

\begin{tabular}{|c|c|c|c|c|}
\hline \multicolumn{2}{|c|}{ Teaching method } & Mean & Std. Deviation & $\mathbf{N}$ \\
\hline Quizzes & $\begin{array}{l}\text { lab } \\
\text { classroom } \\
\text { Total }\end{array}$ & $\begin{array}{l}76.8824 \\
82.1111 \\
79.5714\end{array}$ & $\begin{array}{c}12.45935 \\
9.10649 \\
11.02480\end{array}$ & $\begin{array}{l}17 \\
18 \\
35\end{array}$ \\
\hline Exams & $\begin{array}{l}\text { lab } \\
\text { classroom } \\
\text { Total }\end{array}$ & $\begin{array}{l}77.1765 \\
73.8333 \\
75.4571\end{array}$ & $\begin{array}{l}10.57849 \\
10.63983 \\
10.58951\end{array}$ & $\begin{array}{l}17 \\
18 \\
35\end{array}$ \\
\hline Oral & $\begin{array}{l}\text { lab } \\
\text { classroom } \\
\text { Total }\end{array}$ & $\begin{array}{l}69.0000 \\
66.8889 \\
67.9143\end{array}$ & $\begin{array}{l}9.34077 \\
9.97579 \\
9.58974\end{array}$ & $\begin{array}{l}17 \\
18 \\
35\end{array}$ \\
\hline Final & $\begin{array}{l}\text { lab } \\
\text { classroom } \\
\text { Total }\end{array}$ & $\begin{array}{l}82.5882 \\
79.5556 \\
81.0286\end{array}$ & $\begin{array}{c}8.88157 \\
12.26292 \\
10.70867\end{array}$ & $\begin{array}{l}17 \\
18 \\
35\end{array}$ \\
\hline
\end{tabular}

Chart 2 shows the comparative assessment scores for the face-to-face and lab classes. As opposed to the previous semester comparison this chart shows almost a reverse score effect.

\section{Participants}

\section{CLASSROOM VS. INTERNET 2009}

A convenience sample of 32 students (19 female, 13 males) at Southeastern Louisiana University was used as participants in the present study. Participants were enrolled in Spanish 202 classroom format or Internet format.

\section{Procedure}

The present study aimed at assessing the performance of students in a Spanish 202 course specifically investigating eventual differences in students' performance when the curriculum is delivered in a classroom face-toface format versus Internet format. In order to investigate the researcher's question, a variable representing the teaching method was created, this variable was entered with two levels classroom vs. Internet. Further, four different variables quizzes, exams, oral and final have been created in order to represent the assessment type used to test 
students' knowledge. A 2 (teaching method) X 4 (assessment type) mixed factorial repeated measures analysis of variance was conducted; the variable teaching method was entered into the analysis as a between-subject factor, the variables quizzes, exams, oral and final were entered into the analysis of variance as a within-subject factor with 4 levels. Additionally, a series of paired samples Student's tests were conducted to determine which, if any, combination of means for quizzes, exams, oral and final were significantly different amongst the students enrolled in the classroom format versus those enrolled in the internet format; a correction with Bonferroni's method was necessary to correct for type I error and obtain the adjusted alpha level. Further, to observe any overall difference in students' mean performance relative to teaching method, a third variable G.P.A. was created to represent students' course G.P.A. and used to compute an independent Student's test.

Chart 2: 2004 Classroom vs. Lab Assessment Scores

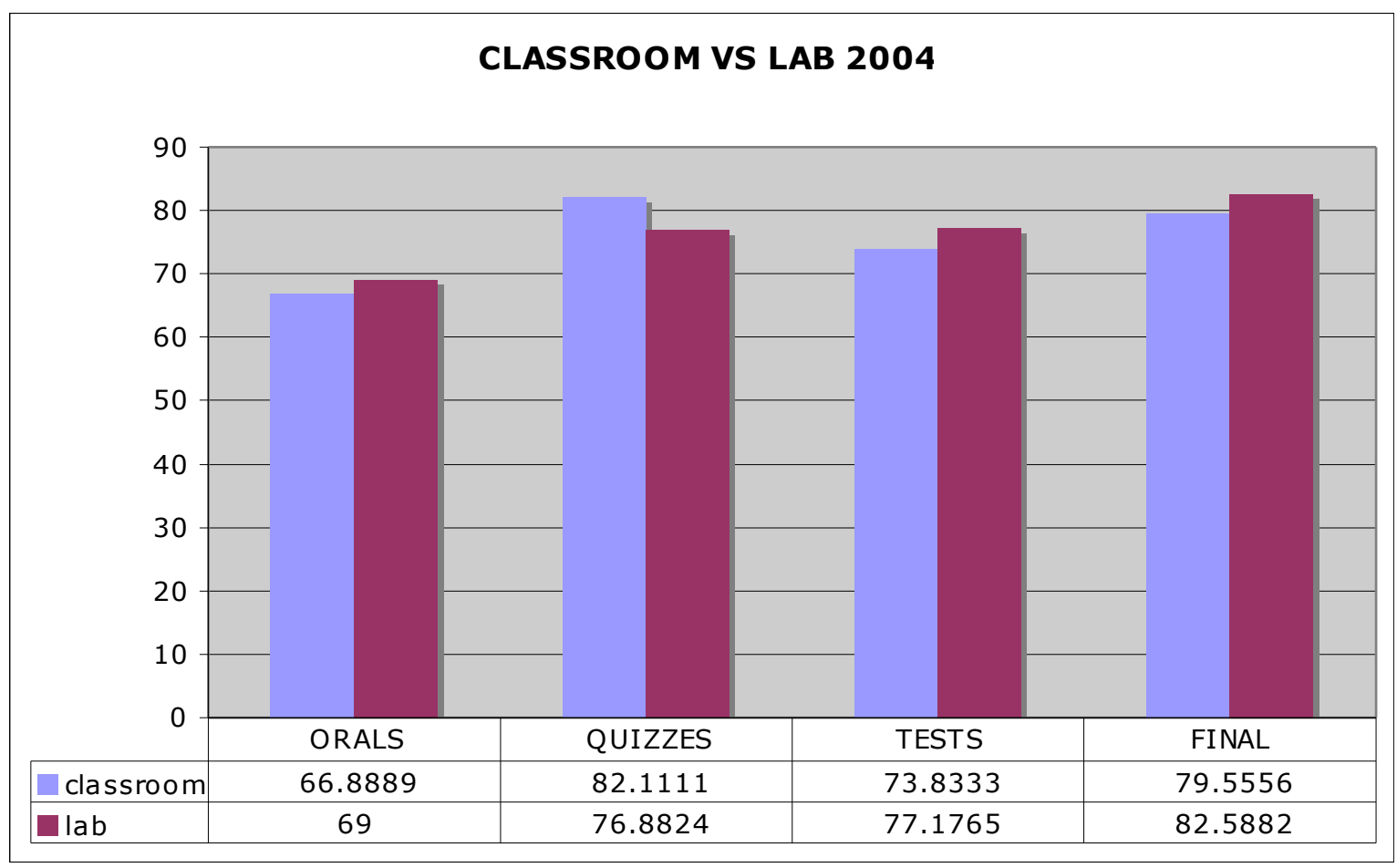

\section{Results}

A 2 (teaching method) X 4 (assessment type) mixed factorial repeated measures analysis of variance has been conducted to assess whether students' performance in Spanish 202 would differ based on the class format, classroom versus internet, they have been exposed to. The analysis showed a significant main effect for assessment ( $F=12.390, p=0.000)$; which suggests that the assessment type used to test students affects their performance. Further analysis has been necessary to locate which assessment type means were significantly different; the results showed the presence of significant differences across conditions for the means of the following pairs, quizzes $(M$ $=76.406, S D=14.524)$ and final $(M=59.843, S D=20.868)$; exam $(M=71.487, S D=18.087)$ and final $(M=$ $59.843, S D=20.868)$; oral $(M=71.156, S D=16.960)$ and final $(M=59.843, S D=20.868)$.

The results of the analysis of variance did not report significant main effect for teaching method $(F=0.015$, $p=0.904)$, suggesting that the teaching method does not affect students' performance. Additionally, no significant interaction has been found between assessment type and teaching method $(F=1.099, p=0.346)$, which suggests that the influence of assessment type on the students' performance does not depend on the teaching method the students were exposed to. Taken altogether, we can say that only assessment type affects students' performance. 
Supplemental analysis was performed to determine the presence of eventual differences between classroom course G.P.A. and Internet course G.P.A; the results did not yield a significant G.P.A. difference $(t=-0.988, p=$ $0.331)$ between the online $(M=69.138)$ and classroom $(M=74.121)$. Table 3 shows the mean scores on each of the four assessments compared to the teaching method. These scores are also shown on Chart 3.

Table 3: Descriptive Statistics, 2009

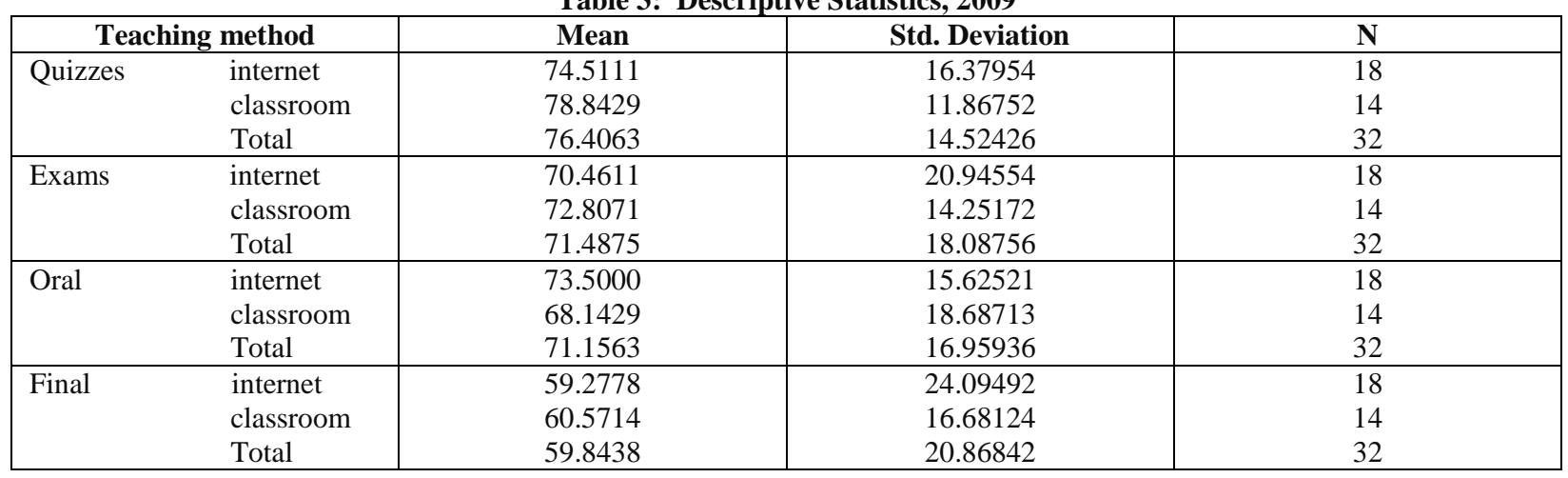

Chart 3 also shows the mean scores on each of the four assessments compared to the teaching method. Even with testing helps for online quizzes such as open book and the possibility of looking up answers online, the classroom still performed better on the quizzes.

Chart 3: 2009 Classroom vs. Internet Assessment Scores

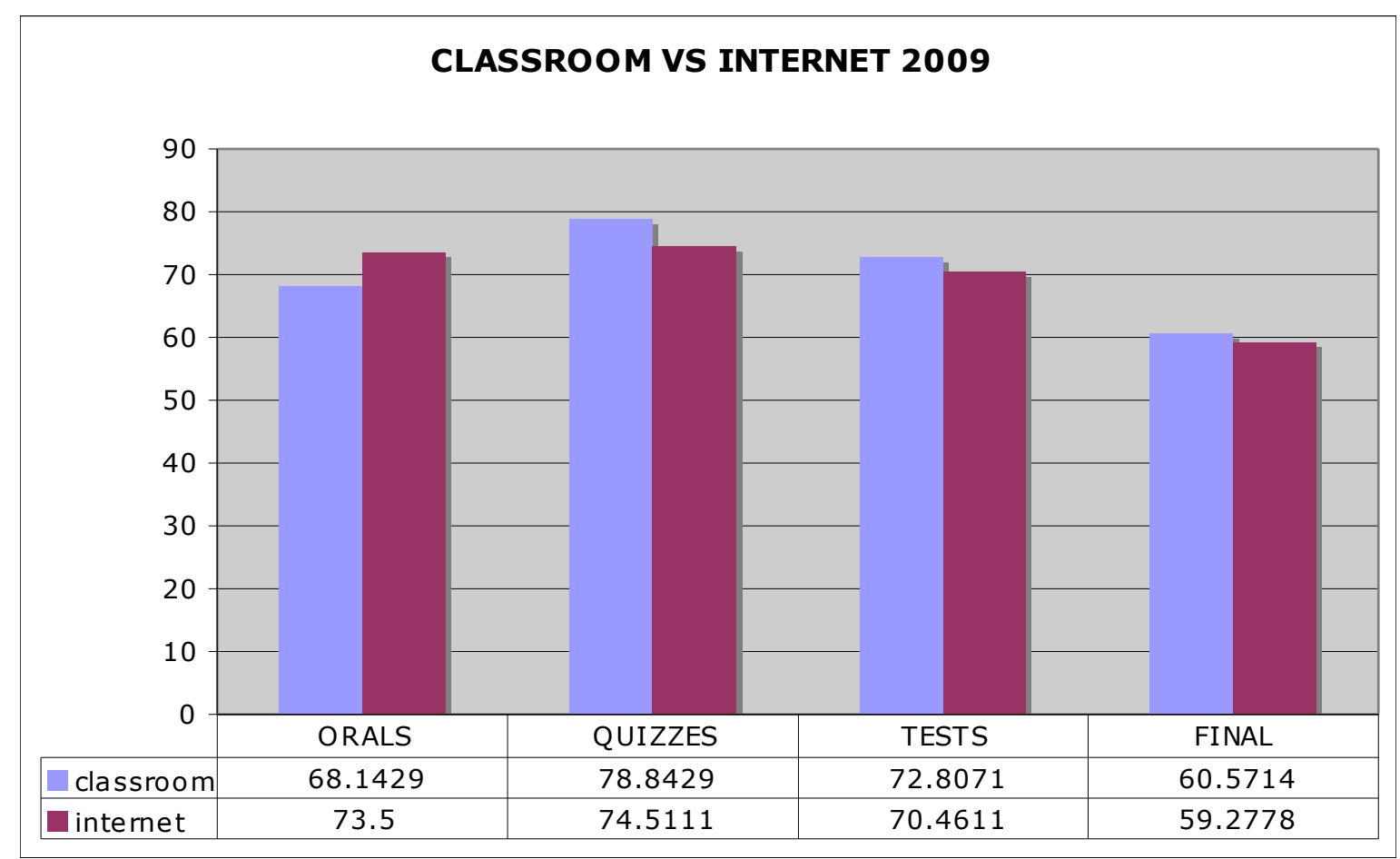


Additionally, all courses were compared for overall course grade point average. Chart 4 shows the course GPA for all semester treatments. Although the differences in GPA did not reach a statistically significant level, the overall course grade for the classroom was equal to or higher than the lab and the online class.

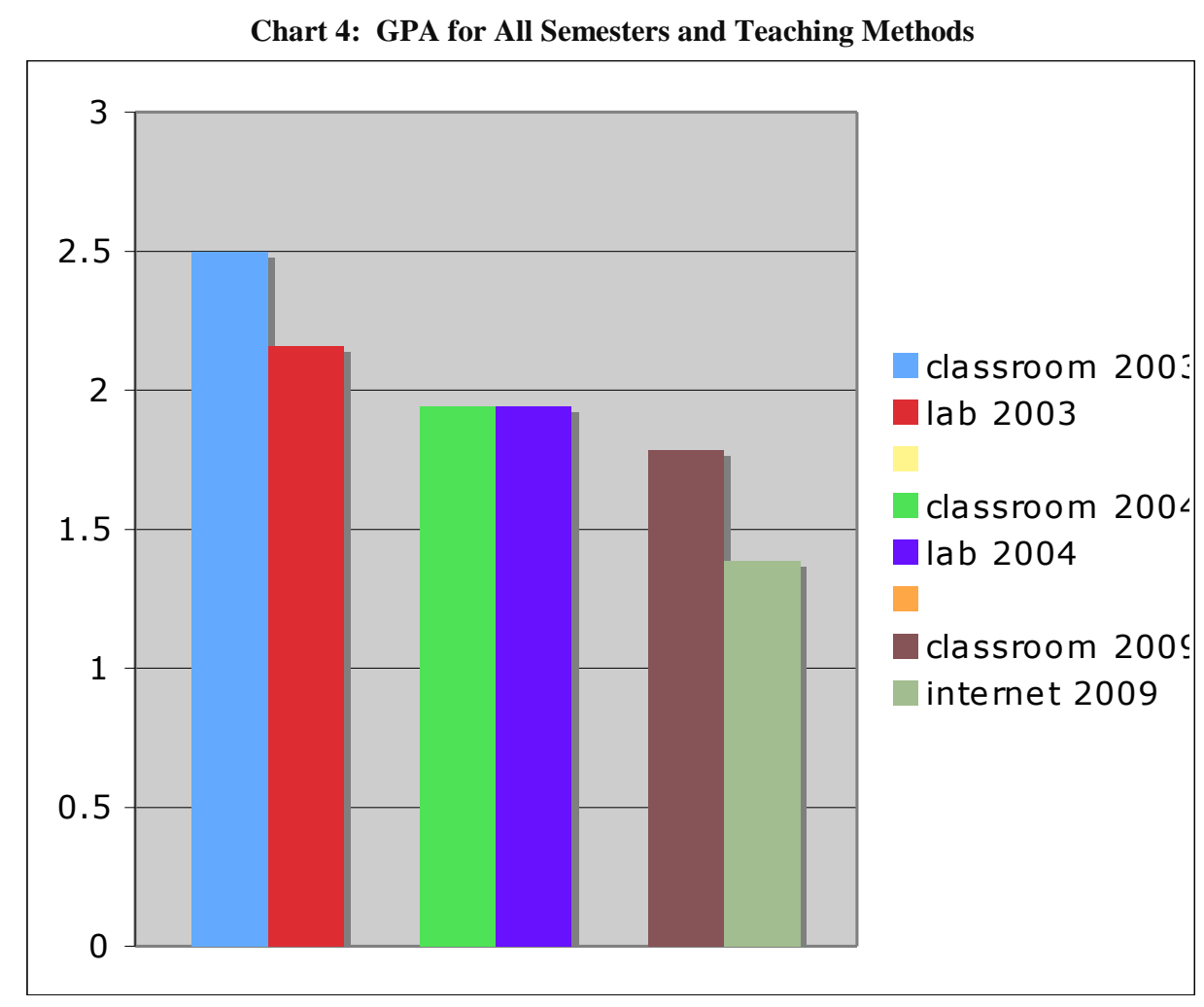

\section{Learner Satisfaction}

Tallent-Runnels, et. al (2006) stated that students liked to move at their own pace and learning outcomes appeared to be the same as in traditional courses. Not surprisingly students with prior training in computers were more satisfied with online courses. Student satisfaction is not usually the reason for choosing an online class. More often it is due to scheduling and other required classes but as instructors we do our best to help them enjoy the class. Kelly (2009) states that "the instructor's "digital" personality can influence student achievement, retention and satisfaction with online courses therefore he encourages instructors to infuse their personalities into their online courses.

Students have reported that online classes require extensive word processing skills, extensive interaction with other students, difficult computer programs, strenuous homework requirements, delayed responses and even additional technology fee costs. On the other hand students can save on travel costs, babysitters and work time lost. They would rather have scheduling flexibility, read information, research and work at their own pace.

Foreign language students may choose online for different reasons. They are often uncomfortable with the second language and choose the online section because they don't have to speak in front of others.

Students from the two semesters taught in the lab had the following comments:

- $\quad$ The lab was a great help with the activities as well as the test. 
- Wish you didn't do it over the computer. I find it distracting and harder to learn.

- $\quad$ Less computer work, no need for headphones when you can speak straight to us.

- Not so much lab work. I get more out of classroom instruction...Do not like going in computer lab everyday!

- I like working on the computers.

- I think she should teach more in the classroom and not on the computers...the earphones are a hassle.

- $\quad$ Computer tasks are good with headphones.

- Good...love the lab.

- $\quad$ The classes held in the computer lab were uncomfortable. I would rather see a person's face when they talk.

- $\quad$ Activities are not helpful. We use the lab during class a lot. We pay her to teach us not a computer.

- $\quad$ Stay out of the lab more.

Table 4 shows students' responses rated by positive or negative items on the Student Opinion of Teaching form. Students rate the class according to planning and management, class environment, enhancement of learning, evaluation of student progress, and quality of instruction. In the first semester the higher number of positive responses could be due to the higher course grades. Second semester's the lab class showed a higher performance and satisfaction rate than the previous semester's lab class. This could indicate that the instructor was more comfortable and the teaching technique was mastered better the second semester. A more likely reason I believe is that the technical problems that were encountered in the first semester causing a loss of class time were either omitted the issue had been resolve. Students may have perceived the instructional quality to be improved with this resolution of a myriad of technical problems. During the two lab semesters only $25 \%$ of students taught in the lab said they would register for [future] Spanish classes with a technology focus that was taught in the lab.

Table 4: Final Course GPA and SOTs (Student Opinion of Teaching)

\begin{tabular}{|l|l|c|l|c|l|}
\hline Class level & \multicolumn{1}{|c|}{ Classroom } & N & \multicolumn{1}{|c|}{ Treatment } & N & SOT \\
\hline SP 101, 2003 & 2.5 & 24 & 2.1578 (LAB) & 19 & All 24 items were equal or higher in the classroom \\
\hline SP 101, 2004 & 1.9444 & 18 & 1.9411 (LAB) & 17 & $\underline{\text { 23 of the 24 items were equal or higher in the Lab }}$ \\
\hline SP 202, 2009 & 1.7857 & 14 & 1.3888 (ONLINE) & 18 & $\begin{array}{l}\text { Very neutral. Exactly [10] of the 20 items were equal } \\
\text { or higher for the classroom }\end{array}$ \\
\hline
\end{tabular}

\section{Instructor Experience}

A major advantage for instructors of online courses is that the scheduling can be more flexible. Instructors could be out of the country with a study abroad group or presenting at a conference without arranging for substitutes. Just as Tallent-Runnels, et. al (2006) found students to be more satisfied with the class if they had previous experience so the instructors who are more technologically advanced would enjoy a class with a tech focus.

Smith, Ferguson \& Caris (2002) reviewed responses from 21 college instructors who state that, "Because of the reliance on text-based communication and a lack of visual cues, every aspect of the course has to be laid out explicitly, in meticulous detail to avoid misunderstandings" (p. 64). This article as well as that of Williams \& Peters (1997) emphasize that online requires a considerable amount of time to design and develop an online class and most instructors agreed the long hours continue during the course to answer questions, clear up ambiguities, etc. They believe that due to the dependence on the written work that often is displayed to other students they seem to result in a deeper level of discourse. This is not likely to occur in foreign language since students are struggling to communicate at a basic conversational level.

Students also feel a sense of anonymity which makes them freer to challenge the instructor; they are sometimes aggressive in ways not see in face-to-face environments appearing to provide more equality between the 
instructor and student (Smith, Ferguson \& Caris, 2002). Students are also more willing to give bad ratings because they feel unattached and anonymous. Each semester I am given lower ratings from online students than from faceto-face students. Narrative statements indicate students feel more isolated and disconnected from teacher and classmates.

The instructor's goal for online instruction is to maintain the same standards and quality of instruction as face-to-face classes. There were some variables that I noticed during the semester of classroom vs. online that could lead to advantages for one or the other.

\section{Classroom benefits not available to online students:}

- $\quad$ Pre-tips for testing

- $\quad$ Clarification during testing

- $\quad$ Group review of quizzes and homework

- $\quad$ Hand written corrections and comments covered during class time, praise stickers on work

- $\quad$ Time limit extended if all students are not finished

- $\quad$ Once due to a cancelled class a quiz was given the following class thus allowing for more study time

Online benefits not available to face-to-face students:

- $\quad$ The audio CD used for the listening comprehension was controlled by students so they could control Windows media by pausing to write, backing up, and replaying.

- Homework and quiz answers can be researched on other websites

- $\quad$ Online quizzes can be open book

\section{SUGGESTIONS FOR FUTURE RESEARCH}

1. Although every generation of students is becoming more accustomed to using computers as a source of education, rate students' computer competence at the beginning of the semester.

2. Rate instructor comfort for online and computer lab use

3. Test differences in student learning styles

4. $\quad$ Compare students at a higher language level

\section{CONCLUSION}

Evaluations of web-based courses in higher education, from 47 reports published between 1996 and 2002, were reviewed and tabulated by Olson \& Wisher (2002) who listed advantages to these courses and suggested that as technology improves, web-based instruction may have an ultimate advantage.

This ultimate advantage may not hold true in foreign languages. Students and instructors agree that foreign language students need personal interaction to overcome anxiety of speaking a foreign language and to master the pronunciation by modeling. Teaching a foreign language is very different from other content areas since there must be more audio, video and interactive communicative activities. Classes taught in the language lab may have actually detracted from time spent in interaction, especially when technical difficulties arose.

The main deterrence to integrating more technology, or to teaching online, is the greater output of time and these longer hours spent online do not correlate to added compensation. Quick questions that could be answered after class turn into several emails. Offering online courses of a quality equal to or greater than comparable face-toface courses takes more time (Cahill \& Catanzaro; DiSalvio, 2007; Dolan, 2008; Smith, Ferguson \& Caris, 2002; Williams \& Peters, 1997). Kelly (2009) describes ways to influence student achievement, retention and satisfaction and do this by more interaction, biographies, audio recordings, screen captures, Skye conversations, and web page creations" (p. 1). If instructors add all these components, they are increasing their online class preparation time immensely. 
What might teaching online mean for those who are not yet tenured? Teaching online is more work and so it is perceived as a threat to productivity in research and service, and this has implications for compensation, promotion, and tenure. Smith, Ferguson \& Caris (2002) conclude that online teaching has some definite advantages that may make the greater work worth the effort for many instructors. This may not be true for many instructors, depending on their position within the department. Those instructors with the technical expertise and the willingness to devote the extra time required for courses with a heavy technological focus might be jeopardizing their future. The additional time spent may detract from valuable time needed to write, present and publish.

Until administration changes the way distance education teachers are evaluated and understand heavier workloads it may not be beneficial. Only if the teacher is tenured faculty could they afford to spend this time that must be taken away from publication efforts.

The benefits to the university are obvious - online courses have lower costs and more students can enroll, avoiding conflicts with their busy schedules and other courses offered. The benefits to students are obvious - online courses provide more flexibility and save costs related to travel, babysitting and other attendance related expenses. The benefit to the instructor is not so obvious. With higher workloads, lower student satisfaction ratings, and time taken from career advancement activities, the value of teaching online may depend on your position within the department and your career goals for the future.

\section{ACKNOWLEDGEMENTS}

The author would like to thank Giorgia Scorsone for her invaluable assistance with statistical comparisons.

\section{AUTHOR INFORMATION}

Claudia Salcedo has a Spanish Masters and a Ph.D. in Curriculum \& Instruction with a major in Foreign Language Instruction and a minor in Educational Technology from Louisiana State University. She is director of the Foreign Language Resource Center and the English Language Lab at Southeastern Louisiana University. She teaches Spanish classes online, advanced levels face-to-face, as well as Spanish for special purposes such as nursing and criminal justice. She also teaches English Language Learning classes. Her research interests are computer assisted language learning and the use of music in the classroom to improve memory and text recall.

\section{REFERENCES}

1. Arbaugh, J. B. (2000). Virtual classroom versus physical classroom: An exploratory study of class discussion patterns and student learning in an asynchronous internet-based MBA course. Journal of Management Education, Vol. 24(2), 213-233.

2. Blake, R., Wilson, N., Cetto, M., \& Pardo-Ballester, C. (2008). Measuring oral proficiency in distance, face-to-face, and blended classrooms. Language Learning \& Technology, Vol. 12(3), pp. 114-127. Available http://llt.msu.edu/vol12num3/blakeetal/

3. Caywood, K. (2003). Online vs. On-campus learning in teacher education. Teacher Education and Special Education: The Journal of the Teacher Education Division of the Council for Exceptional Children, Vol. 26(2), 98-105.

4. Diaz, D. P., Cartnal, R. B. (1999). Students' learning styles in tow classes; online distance learning and equivalent on-campus. College Teaching, v. 47.

5. DiSalvio, . (2007). Revising Workload, Promotion and Tenure Policies for online faculty. Available http://www.magnapubs.com/issues/magnapubs_ff/4_9/news/600668-1.html?s=FF\&p=MFCFEZ

6. Dolan, K. (2008). Comparing Modes of Instruction: The Relative Efficacy of On-Line and In-Person Teaching for Student Learning.

7. Johnson, S. D., Aragon, S. R., Shaik, N., and Palma-Rivas, N. (1999). Comparative analysis of online vs. face-to-face instruction. (ERIC Document No. ED 448 722)

8. Kelly, R. (2009). Instructor's Personality: An essential online course component. Online Classroom. Available http://www.magnapubs.com/issues/magnapubs_oc/9_1/news/602152-1.html?type=pf 
9. Kulik, J. A. (1994). Meta-analysis studies of findings on computer-based instruction. In E. L. Baker, and H. F. O’Neil (Eds.) Technology assessment in education and training (p. 9-33). Hillsdale, NJ: Lawrence Erlbaum Associates.

10. Schutte, J. G. (1997). Virtual teaching in higher education: The new intellectual superhighway or just another traffic jam. Available: http:www.www.csun.edu/sociology/virexp.htm

11. Sims, R. L., Shuman, A. H. (1999). Learning in an online format versus in-class format: An experimental study. T.H.E. Journal, Vol. 26(11), 54-56.

12. Smith, G. G., Ferguson, D., \& Caris, M. (2002). Teaching over the web versus in the classroom: Differences in the instructor experience. International Journal of Instructional Media, Vol. 29(1), 61-67.

13. Student Perspective. (2009). Evaluate online learning versus traditional learning. Available http://www.brighthub.com/education/online-learning/articles/35619.aspx

14. Williams, V. \& Peters, K. (1997). Faculty incentives for the preparations of web-based instruction, in book, web-based instruction, edited by B. H. Khan, 1997 Educational Technology Publications, Englewood Cliffs, New Jersey. 